\title{
Miltefosine Administration in Cats with Refractory Sporotrichosis
}

\author{
Francine dos Santos da Silva, Simone Carvalho dos Santos Cunha, Andrea Regina de Souza Baptista, \\ Vivian dos Santos Baptista, Kássia Valéria Gomes Coelho da Silva, \\ Thais Fernanda Queiroz Coêlho \& Ana Maria Reis Ferreira
}

\begin{abstract}
Background: Sporotrichosis is a zoonosis caused by fungi of the Sporothrix schenckii complex. Cats have important zoonotic potential due to the high parasite load found in the cutaneous lesions. Refractory cases to antifungal therapy are increasing, becoming a public health problem. Miltefosine is a drug with high in vitro activity against Sporothrix brasiliensis. However, this efficacy has not been confirmed in vivo yet and administration has not been studied in the feline species. This study aimed to evaluate the effectiveness and safety of miltefosine administration in cats with resistant sporotrichosis. Materials, Methods \& Results: Ten cats with refractory sporotrichosis were included in this study. Inclusion criteria were previous diagnosis for sporotrichosis associated with therapy with oral antifungals (itraconazole and/or potassium iodide) for more than one year, followed by one of these conditions: incomplete clinical remission, worsening of disease during treatment or recurrence after conventional treatment. Cats underwent clinical and dermatological examinations. Data on lifestyle and previous treatments were provided by the owners. Fungal culture and histochemical techniques were performed in all cats before miltefosine treatment. Blood samples were collected before and during the study for laboratory tests, such as blood count, blood urea nitrogen (BUN), serum creatinine, alanine aminotransferase (ALT) and alkaline phosphatase, as well as serology for Feline Immunodeficiency (FIV) and Feline Leukemia (FeLV). Miltefosine was prescribed at a dosage of $2 \mathrm{mg} / \mathrm{kg}$ orally every $24 \mathrm{~h}$. The animals were monitored by phone during the whole process and reassessed on days 0 , 15,30 and 45 of the treatment. Out of 10 cats, lesions were present on the nose in nine, ears in four, periocular areas in one and limbs in four. One cat received treatment for 45 days, six for 30 days, one for 21 days, one for 15 days and one for 3 days. One cat showed no response to the treatment and nine showed disease progression. Hyporexia and weight loss were the most frequent clinical signs related to miltefosine treatment, followed by sialorrhea, vomiting and diarrhea. Few adverse effects on hematology and biochemistry (mainly renal and hepatic parameters) were observed during the study. Hematocrit decrease was observed in four animals. However, only one cat had hematocrit decrease below normal values (anemia), which was already present before miltefosine administration. Other cats had a decrease of five points. Three cats showed elevation in leucometria and four in plasma protein. In relation to renal and hepatic biochemistry, one animal showed a BUN increase and another one showed a transient increase in ALT. Two animals started the treatment with increased ALT but had no problems during the study and values decreased even during the miltefosine administration. Discussion: Although two cats showed sialorrhea, most owners did not report difficulty in administering the drug orally, representing an advantage of this medication. Weight loss, secondary to gastrointestinal changes, was the most clinically relevant alteration. The most frequent hematological alteration was hematocrit decrease and only the animal that started the study with $20 \%$ hematocrit ended the study with anemia. Renal and hepatic parameters were not significant in the cats of this study. Miltefosine did not lead to sporotrichosis remission in this small population of cats, which reveals that, despite its in vitro efficacy against Sporothrix spp., the drug is not effective in vivo in the feline species. Further studies are needed to investigate the efficacy of this drug in a larger number of cats, and possible reasons for its in vivo ineffectiveness.
\end{abstract}

Keywords: zoonosis, sporotrichosis, resistance, refractory, treatment, miltefosine. 


\section{INTRODUCTION}

Sporotrichosis is a zoonosis caused by species of the pathogenic clade of the genus Sporothrix [6]. The infection usually results from the traumatic or accidental inoculation of the fungus into the skin through thorns or plant material. The cat has important zoonotic potential due to the high parasite load found in the cutaneous lesions, which differentiates it from other species [8].

Several species of $S$. schenckii were isolated from feline and human lesions in Brazil, and Sporothrix brasiliensis is considered the most prevalent species in this current hyperendemics $[8,13,17]$.

Different therapeutic regimens have already been used in affected cats $[9,10,15,16,22]$. However, refractory cases to antifungal therapy are increasing, becoming a public health problem. Several factors may be contributing to the low percentage of cure of feline Sporotrichosis, such as the need for regular administration of medications, difficulty in administering oral medications to cats, and increased virulence of Sporothrix brasiliensis $[1,3]$.

Miltefosine demonstrated antiparasitic activity against Leishmania spp., Histoplasma spp. and Sporothrix spp. The drug has high in vitro activity against Sporothrix brasiliensis, because it causes loss of plasma membrane integrity and effects an increased concentration in the melanin within fungal cells $[4,5,7,21]$. However, this efficacy has not yet been confirmed in vivo and administration has not been studied in the feline species.

This study aimed to evaluate the effectiveness and safety of administration of miltefosine in cats with resistant sporotrichosis.

\section{MATERIALS AND METHODS}

\section{Animals}

The feline owners were notified about the objectives of this research and invited to sign a free and informed consent form. Ten cats (Felis catus), from 2 to 9 years of age, of both genders were included in this study. Cats underwent clinical and dermatological examinations, and data on life style and previous treatments was provided by owners. The animals were allocated into groups according to the distribution of the lesions: L1 (cutaneous lesion in only one site), L2 (cutaneous lesions in two nonadjacent sites) and L3 (cutaneous lesions in 3 or more nonadjacent sites) [19]. Extra-cutaneous clinical signs, cutaneous lesions and lesion site were evaluated. Treatment efficacy criteria were remission of extracutaneous clinical signs and complete healing of the skin and mucosal lesions.

Inclusion criteria were previous fungal culture or histochemical diagnosis for sporotrichosis. All animals were previously treated with oral antifungals (itraconazole and / or potassium iodide) for more than one year without complete clinical remission, worsening of disease during treatment or recurrence after conventional treatment.

\section{Sample collection and laboratory examination}

Fungal culture and histochemical techniques such as Grocott's silver stain were performed in all cats before miltefosine treatment. Samples for fungal culture were collected using a sterile swab in ulcerated lesions and in cases where ulceration was not present (nodular lesions) a fine needle aspiration was performed. Isolation of Sporothrix spp. was performed in Sabouraud dextrose and Micosel agar medium at $25^{\circ} \mathrm{C}$ and after growth of the fungus in the filamentous form, samples were seeded in BHI medium at $37^{\circ} \mathrm{C}$ for the proof of dimorphism and obtaining the yeast form. For the histopathological examination, punch skin biopsy technique was used to obtain an $8 \mathrm{~mm}$ diameter fragment of ulcerated or nodular lesion. Anesthetic protocol was 2-4 mg / $\mathrm{kg}$ of meperidine $\left(\text { Dolantina }^{\circledR}\right)^{1}$ intramuscularly, and $4 \mathrm{mg} / \mathrm{kg}$ of propofol $\left(\text { Propovan }^{\circledR}\right)^{2}$ intravenously. The fragments were fixed in $10 \%$ formaldehyde, processed by routine histopathological methods and sections of $5 \mu$ were stained by the Grocott silver impregnation technique (GMS). The histopathological diagnosis was made observing the morphological characteristics of the fungus; presence of yeasts measuring 2 to $8 \mu \mathrm{m}$, in oval, round and elongated forms; and histochemical staining aspects. The sections were analyzed under a microscope (400x and 1000x).

Blood samples were collected for laboratory tests, such as blood count, BUN, serum creatinine, ALT and alkaline phosphatase before and during the study, as well as serology for Feline Immunodeficiency (FIV) and Feline Leukemia (FeLV) viruses.

\section{Miltefosin administration}

Miltefosine (Milteforan $\left.{ }^{\circledR}\right)^{3}$, a drug available in Brazil and some european countries, was supplied to 
owners, who were responsible for administering the medication at home along with food. The prescribed dosage was $2 \mathrm{mg} / \mathrm{kg}$ orally every $24 \mathrm{~h}$. In the case of hyporexia and / or vomiting, ondansetron $\left(\operatorname{Vonau}^{\circledR}\right)^{4}$ was given at a dose of $0.5 \mathrm{mg} / \mathrm{kg}$ orally every $12 \mathrm{~h}$, and omeprazol $\left(\mathrm{Gaviz}^{\circledR}\right)^{5}$ at the dosage of $1 \mathrm{mg} / \mathrm{kg}$, orally, every $24 \mathrm{~h}$ for the remainder of the treatment with miltefosine. In case of anorexia and / or marked weight loss, the medication was discontinued. Cats that did not improve after 45 days of treatment or had a marked disease worsening at any time were excluded from the study. The cats were monitored during the whole process and reassessed on days $0,15,30$ and 45 days of the treatment, by means of clinical and hematological examinations. Safety was assessed through observation of clinical and laboratory changes based on normal laboratory reference intervals.

\section{RESULTS}

Ten cats with sporotrichosis skin lesions were included in the study, all previously treated for more than one year with itraconazole at a dosage of 100 $\mathrm{mg} / \mathrm{kg} /$ day and recognized as refractory to treatment. Good general condition was observed in nine animals and only one animal exhibited the disseminated cutaneous form, associated with lethargy, dehydration and lymphadenitis. Only one cat had positive viral serology (FIV), although there were no clinical or laboratory differences from the viral serology negative cats. The most frequent extra-cutaneous signs were sneezing and nasal discharge $(5 / 10)$, followed by conjunctivitis $(3 / 10)$ and dyspnea (2/10). In the assessment of lesions distribution, four cats were classified as L1, four as L2 and two as L3. The sites with the highest incidence of lesions were the nose (9/10), ears $(4 / 10)$, limbs (4/10) and periocular area (1/10) [Table 1]. Ulcers and nodules were the predominant cutaneous lesions, which were mostly located on the nose (9/10). Of these nine cats, six exhibited ulcers, three had nodules and one had both an ulcer and a nodule. Other lesions observed were papules, tumors, erythema, crust, excoriation and scars.

All ten cats included in the study had clinical suspicion of sporotrichosis and were being treated with itraconazole and / or potassium iodide for more than one year. Of these ten animals, six animals showed positive fungal culture for Sporothrix spp. In four cases in which fungal culture was not conclusive, the histopathological diagnosis using histochemical technique as the impregnation by Grocott silver was used to identify the fungus agent and its morphological and dyeing characteristics.

Treatment duration was 3 to 45 days. One $(1 / 10)$ cat received miltefosine for 45 days, six $(6 / 10)$ for 30 days, one (1/10) for 21 days and one (1/10) for 15 days. Only one $(1 / 10)$ cat treatment discontinued on the third day, due to its poor clinical condition. The cats in the study showed no improvement in cutaneous and general clinical parameters during treatment with miltefosine at a dosage of $2 \mathrm{mg} / \mathrm{kg}$ orally every $24 \mathrm{~h}$. One cat showed no response to treatment and seven cats showed disease progression.

Miltefosine did not cause adverse/toxic events in the nine studied cats. Owners did not report difficulty in administering this medication orally. Hyporexia and weight loss were the most frequent clinical signs related to treatment $(7 / 10)$, followed by sialorrhea (2/10), vomiting (2/10) and diarrhea (1/10). Sialorrhea and vomiting occurred after 3 days of treatment and were treated with symptomatic therapy. These adverse effects were transient and their control was obtained without interruption of treatment. Diarrhea and dehydration were observed in one (1/10) animal after fifteen days of treatment. One (1/10) animal, which had the disseminated form of the disease and poor clinical condition presented with anorexia, apathy and disease progression after 3 days of treatment. One, three and three cats had a loss of 5\%,7\% and 10-12\% of body weight, respectively (Table 2).

Few hematologic and biochemical (mainly renal and hepatic parameters) changes were found during the assay. Hematocrit decrease was observed in 4 (4/10) animals. However, only one cat had hematocrit decrease below normal values (anemia), which was already present before miltefosine administration. Other cats had a decrease of 5 points. Three cats presented with elevation in leucometria and four cats in plasma protein. In relation to renal and hepatic biochemistry, only one animal showed a BUN increase and one animal showed a transient increase in ALT. Two animals had started treatment with increased ALT but had no problems during the study and values decreased even during miltefosine administration. The hematological and biochemical results found in the study are summarized in Table 3. 


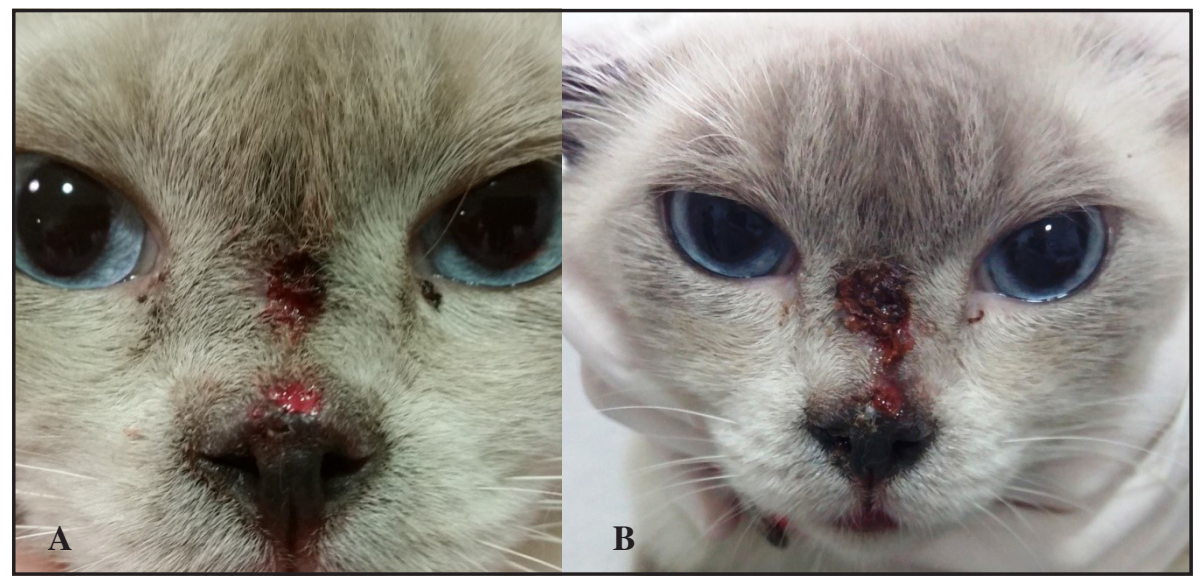

Figure 1. Cat with refractory sporotrichosis before (A) and 45 days after (B) treatment with oral miltefosine. Note evident worsening of the cutaneous lesion (disease progression).

Table 1. Information on age, sex, FIV / FeLV status, distribution and location of skin lesions and laboratorial results of cats with refractory sporotrichosis treated with miltefosine.

\begin{tabular}{cccccccc}
\hline Cat & Age & Gender & FIV/FelV & Lesion distribution & Lesion site & Culture & Grocott \\
\hline 1 & 9 & M & Negative & L2 & Nasal planum/pinna & Positive & + \\
2 & 5 & F & Negative & L1 & Nasal planum & Negative & + \\
3 & 5 & M & Negative & L2 & Nasal planum/ pinna & Negative & + \\
4 & & M & Negative & L3 & Nasal planum/pinna/Periocular/limb/tail & Positive & + \\
5 & 4 & M & FIV + & L2 & limbs & Positive & + \\
6 & & M & Negative & L1 & Nasal planum & Negative & + \\
7 & & M & Negative & L3 & Nasal planum/pinna/limbs & Positive & + \\
8 & & M & Negative & L2 & Nasal planum/limb & Negative & + \\
9 & 4 & F & Negative & L1 & Nasal planum & Positive & + \\
10 & 2 & F & Negative & L1 & Nasal planum & Positive & + \\
\hline
\end{tabular}

FIV (Feline Immunodeficiency Virus); FeLV (Feline Leukemia Virus).

Table 2. Clinical evaluation and weight loss of cats during treatment with miltefosine.

\begin{tabular}{|c|c|c|c|c|}
\hline Cat & $\begin{array}{l}\text { Treatment } \\
\text { (days) }\end{array}$ & Revision 1 (15 days) & Revision 2 (30 days) & $\begin{array}{l}\text { Revision } 3 \\
\text { (45 days) }\end{array}$ \\
\hline 1 & 21 & $\begin{array}{l}\text { Hyporexia, dehydration } 7 \% \text {. diarrhea and lesion } \\
\text { worsening., weight loss (200 g) }\end{array}$ & - & - \\
\hline 2 & 15 & $\begin{array}{l}\text { Salivation, hyporexia, vomiting after miltefosin } \\
\text { administration, lesion with a drier appearance }\end{array}$ & - & - \\
\hline 3 & 45 & $\begin{array}{c}\text { Hyporexia, vomiting in the third miltefosin } \\
\text { administration. lesion with a drier appearance, } \\
\text { weight loss }(200 \mathrm{~g})\end{array}$ & $\begin{array}{l}\text { Sialorrhea, lesion } \\
\text { worsening, weight } \\
\text { loss }(100 \mathrm{~g})\end{array}$ & $\begin{array}{l}\text { Lesion worsening, } \\
\text { weight loss ( } 200 \mathrm{~g})\end{array}$ \\
\hline 4 & 3 & Anorexia, lesion worsening, weight loss (500 g) & - & - \\
\hline 5 & 30 & Lesions without obvious changes & $\begin{array}{l}\text { Anorexia, lesion } \\
\text { worsening, weight } \\
\text { loss }(500 \mathrm{~g})\end{array}$ & - \\
\hline 6 & 30 & Lesion worsening, weight loss (100 g) & $\begin{array}{l}\text { Lesion worsening, } \\
\text { weight loss }(150 \mathrm{~g})\end{array}$ & - \\
\hline 7 & 30 & Lesion worsening, weight gain (270 g) & $\begin{array}{l}\text { Lesion worsening, } \\
\text { weight gain }(330 \mathrm{~g})\end{array}$ & - \\
\hline 8 & 30 & Lesion worsening. & $\begin{array}{l}\text { Lesion worsening, } \\
\text { weight gain }(200 \mathrm{~g})\end{array}$ & - \\
\hline 9 & 30 & $\begin{array}{l}\text { Lesions without obvious changes, } \\
\text { weight gain }(300 \mathrm{~g})\end{array}$ & $\begin{array}{l}\text { Lesion worsening, } \\
\text { weight gain }(100 \mathrm{~g})\end{array}$ & - \\
\hline 10 & 30 & Hiporexia, lesion worsening. & Lesion worsening & - \\
\hline
\end{tabular}


Table 3. Hematological and biochemical results of cats with sporotrichosis during treatment with miltefosine.

\begin{tabular}{|c|c|c|c|c|c|c|c|c|c|c|c|}
\hline & Days & 1 & 2 & 3 & 4 & 5 & 6 & 7 & 8 & 9 & 10 \\
\hline \multirow{4}{*}{$\begin{array}{c}\text { PCV } \\
(24-45 \%)\end{array}$} & 0 & 36 & 43.4 & 43.0 & 37.3 & 43.3 & 37.0 & 20.0 & 30.3 & 38.0 & 41.6 \\
\hline & 15 & 28.9 & 39.9 & 39.2 & 38.6 & 38.7 & 39.7 & 20.2 & 33.8 & - & - \\
\hline & 30 & - & - & 39.0 & - & 47.0 & - & 22.6 & 36.6 & - & - \\
\hline & 45 & - & - & 37.7 & - & - & - & - & - & - & - \\
\hline \multirow{4}{*}{$\begin{array}{c}\mathrm{GL} \\
(6-19 \mathrm{mil} / \mathrm{mm} 3)\end{array}$} & 0 & 13.9 & 20.9 & 11.3 & 11.3 & 15.8 & 10.9 & 41.1 & 8.1 & 11.7 & 15.1 \\
\hline & 15 & 26.3 & 8.7 & 8.8 & 23.8 & 17.1 & 17.8 & 39.0 & 11.0 & - & - \\
\hline & 30 & - & - & 8.3 & - & 26.1 & - & 36.8 & 11.7 & - & - \\
\hline & 45 & - & - & 8.2 & - & - & - & - & - & - & - \\
\hline \multirow{4}{*}{$\begin{array}{c}\text { Platelets } \\
(150-800 \mathrm{mil} / \mu \mathrm{L})\end{array}$} & 0 & 271 & 318 & 418 & 533 & 575 & 271 & 326 & 261 & 382 & 202 \\
\hline & 15 & 125 & 365 & 216 & 246 & 205 & 363 & 542 & 314 & - & - \\
\hline & 30 & - & - & 479 & - & 451 & - & 506 & 332 & - & - \\
\hline & 45 & - & - & 439 & - & - & - & - & - & - & - \\
\hline \multirow{4}{*}{$\begin{array}{c}\text { Plasmatic protein } \\
(3.00-8.00)\end{array}$} & 0 & 9.8 & 9.0 & 8.6 & 7.6 & 9.4 & 7.0 & 8.8 & 7.2 & 7.4 & 7.6 \\
\hline & 15 & 8.2 & 8.4 & 7.8 & 9.2 & 8.8 & 8.2 & 9.2 & 9.0 & - & - \\
\hline & 30 & - & - & 7.4 & - & 9.4 & - & 9.2 & 8.8 & - & - \\
\hline & 45 & - & - & 7.0 & - & - & - & - & - & - & - \\
\hline \multirow{4}{*}{$\begin{array}{c}\text { BUN } \\
(22-64)\end{array}$} & 0 & 29.9 & 48.0 & 63.0 & 34.0 & 33.0 & 62.0 & 55.0 & 49.0 & 47.0 & 72.0 \\
\hline & 15 & 31.0 & 37.0 & 59.0 & 31.0 & 43.0 & 79.0 & 27.0 & 18.0 & - & - \\
\hline & 30 & - & - & 59.0 & - & 33.0 & - & 45.0 & 29.0 & - & - \\
\hline & 45 & - & - & 21.0 & - & - & - & - & - & - & - \\
\hline \multirow{4}{*}{$\begin{array}{l}\text { Creatinine } \\
(0.8 \text { a } 1.80)\end{array}$} & 0 & 1.0 & 1.5 & 1.5 & 0.8 & 1.0 & 1.7 & 1.6 & 1.0 & 1.1 & 0.5 \\
\hline & 15 & 0.5 & 0.8 & 1.4 & 0.7 & 1.4 & 1.6 & 1.1 & 0.8 & - & - \\
\hline & 30 & - & - & 1.4 & - & 1.2 & - & 1.6 & 0.8 & - & - \\
\hline & 45 & - & - & 1.1 & - & - & - & - & - & - & - \\
\hline \multirow{4}{*}{$\begin{array}{c}\text { ALT } \\
(10-80)\end{array}$} & 0 & 90.3 & 27.0 & 42.0 & 20.0 & 33.0 & 33.0 & 69.0 & 38.0 & 27.0 & 87.0 \\
\hline & 15 & 41.0 & 19.0 & 47.0 & 64.0 & 38.2 & 45.0 & 82.0 & 38.0 & - & - \\
\hline & 30 & - & - & 24.0 & - & 13.0 & - & 52.0 & 62.0 & - & - \\
\hline & 45 & - & - & 15.0 & - & - & - & - & - & - & - \\
\hline \multirow{4}{*}{$\begin{array}{c}\text { ALP } \\
(15-80)\end{array}$} & 0 & 52.6 & 18.0 & 15.0 & 22.0 & 15.0 & 16.0 & 55.0 & 15.0 & 24.0 & 13.0 \\
\hline & 15 & - & 24.0 & 15.0 & 16.0 & 31.0 & 27.0 & 20.0 & 20.0 & - & - \\
\hline & 30 & - & - & 19.0 & - & 19.0 & - & 41.0 & 41.0 & - & - \\
\hline & 45 & - & - & 17.0 & - & - & - & - & - & - & - \\
\hline
\end{tabular}

PCV (Packed Cell Volume); GL (Global leucometry); ALT (Alanine aminotransferase); ALP (Alkaline Phosphatase).

\section{DISCUSSION}

To the authors' knowledge, this is the first time that miltefosine was administered to cats with refractory sporotrichosis for evaluation of its effectiveness and safety. In the present study, miltefosine did not lead to sporotrichosis remission in this small population of cats, which reveals that, despite its in vitro efficacy against Sporothrix spp., the drug is not effective in vivo in the feline species. The reasons for clinical failure are undetermined at this time.

Most of observed skin lesions were nodules and ulcers in the nasal planum. All the negative cases in the fungal culture were of samples collected in the nasal planum, (3/4) in nodules and (1/4) in ulcer. It was observed an inverse correlation between the presence of granulomas and the number of fungal structures of S. schenckii in the inflammatory infiltrate of cats [19]. Although fungal culture is the gold standard technique for the diagnosis of sporotrichosis [18], fungal organisms in cats are considered highly characteristic in the tissues and histopathology is a viable and quicker option for the diagnosis of this mycosis in cats, especially when fungal isolation is not possible [14,20].

The adverse effects to miltefosine observed in this study were hyporexia (7/10), sialorrhea (2/10), vomiting (2/10) and diarrhea (1/10). Weight loss, secondary to gastrointestinal changes, was the most clinically rel- 
evant alteration and was present in nine (9/10) animals of the study, of which, one cat had $5 \%$ loss of body weight, three cats had 7\%, and three cats had 10-12\% loss of body weight. In studies on the safety of the use of Miltefosine in dogs as a single therapy or associated with allopurinol, transient self-limiting and reversible episodes of vomiting were the main side effects $[2,11,12,23]$. Although two cats showed sialorrhea, most owners did not report difficulty in administering the drug orally, representing an advantage of this medication.

The most frequent hematological alteration was hematocrit decrease, which occurred in four (4/10) animals and only the animal that started the study with $20 \%$ hematocrit ended the study presenting anemia. In patients with visceral leishmaniasis (VL), rapid recovery from anemia, leukopenia and thrombocytopenia were observed [21].

Renal and hepatic parameters were not significant in cats of this study. Only one animal had a slight BUN increase and one animal showed a transient increase in ALT. One animal that started treatment with elevated ALT followed with decreasing of these values throughout the study. These data corroborate with several studies on the safety of the use of miltefosine in dogs, which observed low effect on hematology and renal and hepatic functions $[11,23]$.

\section{CONCLUSION}

Miltefosine did not lead to clinical remission of refractory sporotrichosis to conventional treatment with itraconazole and / or potassium iodide in this small cohort of cats. Further studies are needed to investigate the efficacy of this drug in feline species in a larger number of animals, and possible reasons for its in vivo ineffectiveness in feline species.

\section{MANUFACTURERS}

${ }^{1}$ Sanofi. São Paulo, SP, Brazil.

${ }^{2}$ Cristália Produtos Químicos e Farmacêuticos. Rio de Janeiro, RJ, Brazil.

${ }^{3}$ Virbac. São Paulo, SP, Brazil.

${ }^{4}$ Biolab Sanus Farmacêutica. Taboão da Serra, SP, Brazil.

${ }^{5}$ Agener União. Taboão da Serra, SP, Brazil.

Funding. The funding for this research was provided by FAPERJ (Fundação de Amparo à Pesquisa do Estado do Rio de Janeiro).

Ethical Approval. This study was submitted and approved by the Ethics Committee on Animal Use (CEUA) of the Fluminense Federal University (n.810/2016).

Declaration of interest. The authors declared no potential conflicts of interest with respect to the research, authorship, and/or publication of this article.

\section{REFERENCES}

1 Almeida-Paes R., Oliveira M.M., Freitas D.F., Valle A.C., Gutierrez-Galhardo M.C. \& Zancopé-Oliveira R.M. 2017. Refractory sporotrichosis due to Sporothrix brasiliensis in humans appears to be unrelated to in vivo resistance. Medical Mycology. 55: 507-517.

2 Andrade H.M., Toledo V.P., Pinheiro M.B., Guimarães T.M., Oliveira N.C., Castro J.A., Silva R.N., Amorim A.C., Brandão R.M., Yoko M., Silva A.S., Dumont K., Ribeiro Jr. M.L., Bartchewsky W. \& Monte S.J. 2011. Evaluation of miltefosine for the treatment of dogs naturally infected with L. infantum (=L. chagasi) in Brazil. Veterinary Parasitology. 181(2-4): 83-90.

3 Arrillaga-Moncrieff I., Capilla J., Mayayo E., Marimon R., Mariné M., Gené J., Cano J. \& Guarro J. 2009. Different virulence levels of the species of Sporothrix in a murine model. Clinical Microbiology and Infection. 15(7): 651-655.

4 Borba-Santos L.P., Gagini T., Ishida K., Souza W. \& Rozental S. 2015. Miltefosine is active against Sporothrix brasiliensis isolates with in vitro low susceptibility to amphotericin B or itraconazole. Journal of Medical Microbiology. 64: 415-422.

5 Brilhante R.S.N., Malaquias A.D.M., Caetano E.P., Castelo-Branco D.S., Lima R.A., Marques F.J., Silva N.F., Alencar L.P., Monteiro A.J., Camargo Z.P., Bandeira T.J., Rodrigues A.M., Cordeiro R.A., Moreira J.L., Sidrim J.J. \& Rocha M.F. 2014. In vitro inhibitory effect of miltefosine against strains of Histoplasma capsulatum var. capsulatum and Sporothrix spp. Medical Mycology. 52: 320-325.

6 De Beer Z.W., Duong T.A. \& Wingfield M.J. 2016. The divorce of Sporothrix and Ophiostoma: solution to a problematic. Studies in Mycology. 83: 165-191.

7 Greene C.E. 2006. Antifungal chemotherapy. In: Greene C.E. (Eds). Infectious diseases of the dog and the cat. Philadelphia: Saunders Elsevier, pp.542-550.

8 Gremião I.D.F., Miranda L.H.M., Reis E.G., Rodrigues A.M. \& Pereira S.A. 2017. Zoonotic epidemic of sporotrichosis: Cat to human transmission. PLOS Pathogens. 13(1): 1-7. 
9 Gremião I.D.F., Pereira S.A., Rodrigues A.M., Figueiredo F.B., Nascimento Jr. A., Santos I.B. \& Schubach T.M.P. 2006. Tratamento cirúrgico associado à terapia antifúngica convencional na esporotricose felina. Acta Scientiae Veterinariae. 34(2): 221-223.

10 Gremião I.D.F, Schubach T.M.P, Pereira S.A., Rodrigues A.M., Honse C.O. \& Barros M.B.L. 2011. Treatment of refractory feline sporotrichosis with a combination of intralesional amphotericin B and oral itraconazole. Australian Veterinary Journal. 89(9): 346-351.

11 Mateo M., Maynard L., Vischer L., Bianciardi P. \& Miró G. 2009. Comparative study on the short term efficacy and adverse effects of miltefosine and meglumine antimoniate in dogs with natural leishmaniosis. Parasitology Research. 105: $155-162$.

12 Miró G., Oliva G., Cruz I., Cañavate C., Mortarino M., Vischer C. \& Bianciardi P. 2009. Multicentric, controlled clinical study to evaluate effectiveness and safety of miltefosine and allopurinol for canine leishmaniosis. Veterinary Dermatology. 20: 397-404.

13 Montenegro H., Rodrigues A.M., Dias M.A., Silva E.A., Bernardi F. \& Carmargo Z.P. 2014. Feline sporotrichosis due to Sporothrix brasiliensis: an emerging animal infection in São Paulo, Brazil. BMC Veterinary Research. 10: 269.

14 Pereira S.A., Menezes R.C., Gremião I.D.F., Silva J.N., Honse C.O., Figueiredo F.B., da Silva D.T., Kitada A.A., dos Reis E.G. \& Schubach T.M.P. 2011. Sensitivity of cytopathological examination in the diagnosis of feline sporotrichosis. Journal of Feline Medicine and Surgery. 13: 220-223.

15 Pereira S.A., Schubach T.M.P., Gremião I.D.F., Silva D.T., Figueiredo F.B., Assis N.V. \& Passos S.R.L. 2009. Aspectos terapêuticos da esporotricose felina. Acta Scientiae Veterinariae. 37: 311-321.

16 Reis E.G., Gremião I.D.F., Kitada A.A., Rocha R.F., Castro V.S., Barros M.B., Menezes R.C., Pereira S.A. \& Schubach T.M.P. 2012. Potassium iodide capsule in the treatment of feline sporotrichosis. Journal of Feline Medicine and Surgery. 14: 399-404.

17 Rodrigues A.M., De Hoog G.S. \& Camargo Z.P. 2016. Sporothrix Species Causing Outbreaks in Animals and Humans Driven by Animal-Animal Transmission. PLOS Pathogens. 12(7): 1-7.

18 Schubach T.M.P., Menezes R.C. \& Wanke B. 2012. Sporotrichosis. In: Greene C.E. (Eds). Infectious Diseases of the dog and cat. 4th edn. St Louis: Elsevier, pp.645-650.

19 Schubach T.M., Schubach A., Okamoto T., Barros M.B., Figueiredo F.B., Cuzzi T., Fialho-Monteiro P.C., Reis R.S., Perez M.A. \& Wanke B. 2004. Evaluation of an epidemic of sporotrichosis in cats: 347 cases (1998-2001). Journal of American Veterinary Medical Association. 224: 1623-1629.

20 Silva J.N., Passos S.R.L., Menezes R.C., Gremião I.D.F., Schubach T.M.P., Oliveira J.C., Figueiredo A.B.F. \& Pereira S.A. 2015. Diagnostic accuracy assessment of cytopathological examination of feline sporotrichosis. Medical Mycology. 53(8): 880-884.

21 Sindermann H. \& Engel J. 2006. Development of miltefosine as an oral treatment for leishmaniasis. Transactions of the Royal Society of Tropical Medicine and Hygiene. 100 (Suppl 1): 17-20.

22 Souza C.P., Lucas R., Ramadinha R. \& Pires T.B. 2016. Cryosurgery in association with itraconazole for the treatment of feline sporotrichosis. Journal of Feline Medicine and Surgery. 18(2): 137-143.

23 Woerly V., Maynard L., Sanquer A. \& Eun H.M. 2009. Clinical efficacy and tolerance of miltefosine in the treatment of canine leishmaniosis. Parasitology Research. 105(2): 463-469. 